\title{
Psychological impact of school closure and social isolation on female students during Covid-19: A case study from Bangladesh
}

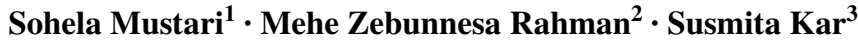

Accepted: 5 September 2021 / Published online: 10 November 2021

(C) UNESCO IBE 2021

\begin{abstract}
This article describes the socio-psychological effects of school closure on school-going urban girls in Dhaka, Bangladesh, during the Covid-19 pandemic. It illustrates the life of urban students in Bangladesh during the school-closing time and relates it to their previous normal life. It asserts that the strengths of traditional schools have important relevance to socialization, which was significantly disturbed during the pandemic due to home confinement. Based on both qualitative and quantitative data, the following components led to an understanding of the schools' role in the socialization of urban female students in Bangladesh: emotional attachments, interpersonal interactions, and physical activity. During confinement, the absence of these components put the students' socialization process at risk, resulting in socio-psychological changes in activities and behavioral patterns. Finally, the article recommends not considering online classes as the "new normal"; working toward vaccination and obtaining suitable health equipment for the reopening of traditional schools will do more to ensure the socio-psychological health of future generations.
\end{abstract}

Keywords Socialization $\cdot$ School closure $\cdot$ Coronavirus $\cdot$ Bangladesh $\cdot$ Urban

Sohela Mustari

mustari.soc@brur.ac.bd

Mehe Zebunnesa Rahman

mehe.rahman@northsouth.edu

Susmita Kar

susmitak20@gmail.com

1 Department of Sociology, Begum Rokeya University, Modern, Rangpur City Bypass Park, Rangpur 5404, Bangladesh

2 Department of Management, School of Business and Economics (SBE), North South University, Dhaka 1229, Bangladesh

3 Department of Public Health, Faculty of Allied Science, Daffodil International University, 102/1, Sukrabad Mirpur Rd, Dhaka 1207, Bangladesh 
Covid-19 causes severe acute respiratory syndrome and was detected in Wuhan, China, in early December 2019, after which time it spread throughout the world (Bhimraj et al. 2020; Dong et al. 2020). The World Health Organization (WHO) declared Covid-19 a pandemic, based on its severity and its global transmission (Lee et al. 2020; Mehta et al. 2020). The death rate from Covid-19 ranges from $0.47 \%$ to over $13 \%$, depending on access to health care, availability of testing, and socio-demographic variables in different countries (Hanafiah et al. 2020).

The measures for reducing the impact of Covid-19 are clearly stated by WHO and include maintaining social distance; staying within one's own territory; washing hands properly; and closing all nonessential institutions, including schools, mosques, parks, and other public facilities (Dev and Sengupta 2020).

Most countries have instituted social distancing measures (Child 2020). As soon as Covid-19 was declared a pandemic, several countries confirmed widespread closures of schools for an indefinite period (Armitage and Nellums 2020). School closures can help the biological safety of children but may negatively affect their social life. Many researchers and policy makers focus on the biological need to save lives; however, the effects of Covid-19 on children's social life is also important (Mustari and Rahman 2020). Some research has used a social science lens to look at the impact of Covid-19 on various social groups, but few empirical studies have described the probable effects of school closings on children. Therefore, the primary objective of this study is to fill that gap by highlighting the effects of school closures during the Covid-19 crisis on school-going children. In addition, a specific objective is to understand the socio-psychological effects of school closures on school-going girls in urban areas of Bangladesh.

\section{Covid-19 and school closures in Bangladesh}

A national survey in China reported that the country's strict quarantine measures and isolation process had affected people psychologically, eliciting panic disorder, anxiety, and depression (Qiu et al. 2020). People around the world have struggled with the changes in their daily routines, increased uncertainty in life, and insecurity about their health and future. In addition, those working from home had to balance their work and household responsibilities. Home confinement may have had a negative impact on daily activity by changing people's sleeping patterns and even leading to insomnia (Altena et al. 2020).

Bhutani and Cooper (2020) found that home confinement caused weight gain and obesity. They stated that the lack of physical exercise, due to gym closures, and changes in eating behavior caused individuals to become overweight and obese. The reduction in outdoor activities and social interactions during the pandemic increased depression among children (Xie et al. 2020). Although infection and death rates from Covid-19 have been comparatively lower for children than for other age groups (Armitage and Nellums 2020), children around the world are facing other challenges during home confinement due to Covid-19. School closures have resulted in restrictions in learning, socializing, and physical activity (Child 2020; Sinha et al. 2020). These impacts make school-going children vulnerable and can interfere with their normal socialization process. Thus, for children, the greatest threat arguably has not been Covid-19, but rather the threat to them from the education system, which has been shut for an indefinite period. 
In response to Covid-19, the Bangladesh government ordered a nationwide school closure as an emergency measure to prevent the spread of the virus. On March 16, 2020, the Bangladesh government closed all educational institutions, starting March 17. From that day until today (August 5, 2020), all educational institutions remained closed. Approximately two lakhs of educational institutions in Bangladesh support more than four crores of students from different levels. Although other institutions gradually reopened, the Education Ministry of Bangladesh was firm about closing all educational institutions until September 2020 if the severity of the pandemic remained unchanged. From the rates of death and infection, some researchers and public health experts hypothesized there was little chance of reducing the number of infected persons before September. Considering the situation, and with the permission of the proper authorities, some of the schools in the urban regions decided to continue teaching with online classes.

Although the Bangladesh government declared itself to be "Digital Bangladesh", internet facilities were not widely available, due to economic instability and low technological proficiency. Hence, the government took the initiative to deliver online classes through national television (i.e., the government's television center), which can reach remote areas of Bangladesh, as long as other facilities are unavailable to students. In addition to the government's delivery of classes through television, a few schools used online classes to continue their regular academic activities. However, this approach had different impacts on the young members of society. Therefore, in this article, we intend to determine the socio-psychological effects of school closure on school-going girls from urban areas in Bangladesh.

\section{Conceptual framework and methodology}

The conceptual framework for this study incorporates the effects of Covid-19 on socialization and such factors as stress and anxiety (Figure 1). Socialization is the process by which an individual learns the desirable and appropriate standards, skills, motives, attitudes, and behaviors for a particular society. Families, peers, schools, and the media are the most important and well-established agents in the socialization process (Parke and Buriel 2007). These agents work together rather than autonomously. Although stress and anxiety are subjects of psychology, they can also be understood as social phenomena (Putwain 2007).

We used qualitative and quantitative methods to explore and analyze the impacts of school closure on school-going children in Dhaka, Bangladesh. To achieve our objectives, we used in-depth interviews and survey techniques. The survey was conducted with school-going girls ages 6 to 17 years old. Although school in Bangladesh starts at 6 years old and ends at 16 years old, the pandemic caused the secondary school certificate (SSC)
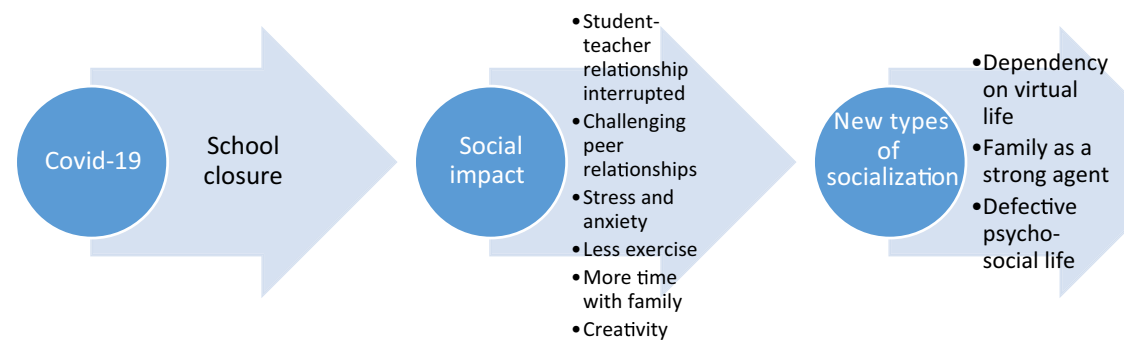

Figure 1 Conceptual framework of school closure and its effects on the child's socialization 
to be published late, which added one year to the usual age. The survey ran from May 11 to May 25, 2020.

The data collection activities were done during the lockdown, while the public holiday for educational institutes continued. With a few exceptions, students were not allowed to have any social interactions. Students in this age group are considered to be minors, so the surveys were distributed to them with the prior permission of their parents through Google forms that were sent to their parents' email addresses. We communicated with the parents through social media, using various parenting forums on Facebook.

The respondents were children from schools in Dhaka (i.e., in North Dhaka and South Dhaka). They were using different curricula, including Bangla, English, English version, and others. Female students were chosen purposively, using a convenient sampling procedure, in various locations of Dhaka.

We used qualitative and quantitative methods to determine the effects of school closure during the pandemic on school-going female students. We used mixed methods to collect the data. First, we conducted the qualitative part of the study and then continued with the quantitative part. A structured interview schedule was used to collect the required information about socio-demographic status; activities during home confinement; attitudes toward school closure, and feelings regarding schools, teachers, and peer groups. A total of 122 female respondents, aged 6 to 17 years old, participated in the survey under their parents' supervision.

To get an in-depth understanding of the effects of home confinement on school closure, we conducted in-depth interviews with 12 respondents. The 12 respondents were selected purposively from different socio-demographic backgrounds and varied by age, medium of school, and number of siblings. The 12 respondents took part in both qualitative and quantitative sections. Moreover, we conducted informal discussions with six parents, to increase the validity and reliability of the collected data.

We analyzed the collected data with descriptive statistics, using frequency distribution and percentages. The qualitative data were taken from the direct narrative speech of respondents, and quotations were identified to be used in the descriptive analysis.

\section{Results and findings}

A total of 122 respondents ages 6 to 17 years old participated in this study (Table 1). The highest number of respondents $(51.64 \%)$ was $10-13$ years old. The fathers of the respondents were mostly (68.90\%) employed. However, their mothers were mostly (44.30\%) homemakers. Almost two-thirds (63.10\%) of the respondents had only one sibling; $57.40 \%$ had family members other than parents and siblings. In cases where respondents lived with more than parents and siblings, the additional persons were maternal or paternal grandmothers or maidservants $(33.30 \%$ for each category, respectively). Almost one-quarter $(23.80 \%)$ of the respondents had no sibling, and $42.60 \%$ had no other member except their parents and siblings.

Of the 122 respondents, 53 were from the Bangla medium schools and 39 were from English-version schools (Table 2). Except for one, all respondents said that during the Covid-19 crisis, their schools closed on March 17, 2020. To continue formal education, the school authorities managed to find an alternative via virtual classes. More than $80 \%$ of the respondents had online classes during this so-called "vacation" period. However, more than $65 \%$ stated they do not like online classes because they thought these classes made them miss their real school, school friends, and teachers (37.50\%). Twenty-five percent of 
Table 1 Respondents' demographic information

\begin{tabular}{|c|c|}
\hline Item & $n(\%)$ \\
\hline \multicolumn{2}{|l|}{ Age distribution } \\
\hline $6-9$ years old & $26(21.31) \%$ \\
\hline $10-13$ years old & $63(51.64 \%)$ \\
\hline 14-17 years old & $33(27.05 \%)$ \\
\hline \multicolumn{2}{|l|}{ Father's occupation } \\
\hline Job & $84(68.90 \%)$ \\
\hline Business & $27(22.10 \%)$ \\
\hline Others & $11(9.00 \%)$ \\
\hline \multicolumn{2}{|l|}{ Mother's occupation } \\
\hline Homemaker & $54(44.30 \%)$ \\
\hline Job & $45(36.90 \%)$ \\
\hline Business & $11(9.00 \%)$ \\
\hline Others & $12(9.84 \%)$ \\
\hline \multicolumn{2}{|l|}{ Number of siblings } \\
\hline No sibling & $29(23.80 \%)$ \\
\hline Only one sibling & $77(63.10 \%)$ \\
\hline More than one sibling & $16(13.10 \%)$ \\
\hline \multicolumn{2}{|c|}{$\begin{array}{l}\text { Do you have any other family members except your } \\
\text { parents and siblings? }\end{array}$} \\
\hline Yes & $70(57.40 \%)$ \\
\hline No & $52(42.60 \%)$ \\
\hline \multicolumn{2}{|c|}{$\begin{array}{l}\text { Relationship with another member/members (more than } \\
\text { one response counted) }\end{array}$} \\
\hline Maternal grandmother & $24(33.30 \%)$ \\
\hline Maternal grandfather & $10(13.90 \%)$ \\
\hline Paternal grandmother & $24(33.30 \%)$ \\
\hline Paternal grandfather & $15(20.80 \%)$ \\
\hline Maidservant & $24(33.3 \%)$ \\
\hline Uncle & $17(23.60 \%)$ \\
\hline Aunt & $16(22.20 \%)$ \\
\hline Cousin & $4(5.20 \%)$ \\
\hline
\end{tabular}

the respondents complained that online classes could not create the right classroom environment for understanding their lessons. Some respondents criticized online classes, saying that teachers took more time to reply (5\%), classes were very uncomfortable and chaotic (15\%), and the explanations were very hard to understand (17.5\%).

A 13-year-old respondent from an English medium school expressed her dissatisfaction with online classes by stating, "It is hard to understand what the teacher is explaining. I cannot ask for clarification and the teacher also takes time to answer. I do not feel online classes are perfect for me". Another 13-year-old respondent of a Bangla medium school stated her dissatisfaction with online classes by saying, "I don't like this online class because I am not comfortable and it is very boring to stare for a long time at a computer screen. Sometimes I cannot concentrate my mind towards the speech". Another 13-year-old respondent from an English medium school expressed her feelings about online classes as follows: 
Table 2 Information about the school of the respondents

\begin{tabular}{ll}
\hline Items & $N(\%)$ \\
\hline Mediums of curriculum in the school & \\
Bangla & $53(43.4 \%)$ \\
English & $29(23.8 \%)$ \\
English version & $39(32.0 \%)$ \\
Others & $1(0.8 \%)$ \\
Is your school (classroom-based school) open now? & \\
No & $121(99.2 \%)$ \\
Yes & $1(0.8 \%)$ \\
If no, do you like the vacation? & $33(27.3 \%)$ \\
Yes & $88(72.7 \%)$ \\
No & \\
Do you have online classes during the vacation? & $100(82.0 \%)$ \\
Yes & $22(18.0 \%)$ \\
No & \\
Do you like online classes? & $82(67.2 \%)$ \\
Yes & $40(32.8 \%)$ \\
No &
\end{tabular}

Because it seems quite harder to focus in the class and the rules and regulations of one regular class are not being followed here. The environment of a school's classroom cannot be presented through an online class. People usually lack to express any problems towards any subject. And not all individuals are provided with the proper internet connection thus causing problem for them to join the classes which they would not face if the classes were conducted in an actual classroom.

A 15-year-old respondent from an English-version school said, "I am not getting real school atmosphere in these classes. I cannot communicate with my teacher and friends, which I can in real school. Here I need to do class alone, sitting inside the screen".

Although the respondents understood the pandemic situation, most of them did not like the mandatory vacation. The results showed that $56.81 \%$ of the respondents missed their friends and wanted to meet them. However, $67.20 \%$ of the respondents said they liked their online classes. The reasons they gave for liking their online classes included new opportunities to continue their studies $(63.41 \%)$, the opportunity to continue their relationships with friends and teachers $(26.83 \%)$, and the relatively less complicated nature of online classes compared with going to a physical school $(9.76 \%$; Figures 2 and 3).

A 13-year-old respondent from an English medium school supported the implementation of vacation and expressed her positive feelings because she could spend more time with her family: "I like this vacation because I get to stay home and spend more time with my sisters. Also because I can help around more in the house". A similar statement was given by a grade- 4 student from a Bangla medium school: "I like this vacation because we can still do a lot of stuff and I can spend time with my parents and my brother". However, a 12-year-old from a grade-6 class said, "I like this vacation because I can sleep more than school time and I can read and enjoy reading with my own according to my interest. I do not like the pressures of examination and grading of school". 
14

12

12
10

\section{8}

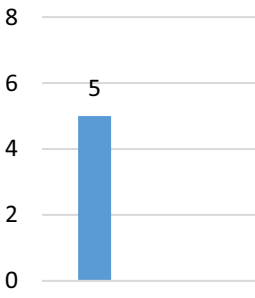

No pressure of homework
7

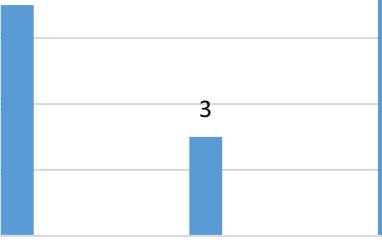

I can sleep more I can spend more I can play longer I am introvert, so than school time time with my family members

12

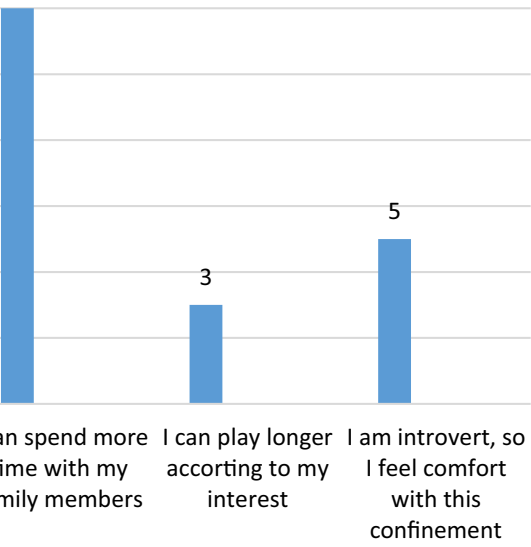

number percentage

Figure 2 Reasons for liking the vacation

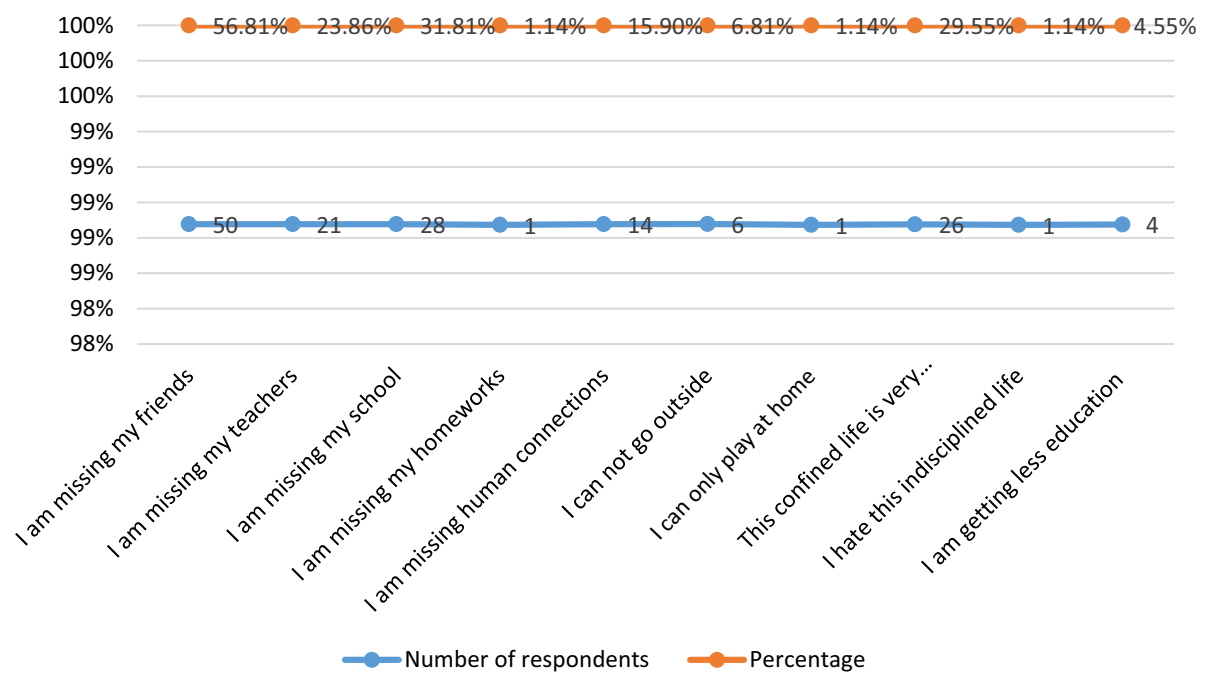

Figure 3 Reasons for not liking the vacation

Many students liked online classes because they created a means of communication with their friends and teachers and a way to continue their studies (Figure 4). A 16-yearold English medium student responded,

I like online classes because I can see my friends and classmates. I can also communicate with my teachers even during these bizarre times. It also helps to understand the power of technology and also do not let a student miss her study. 


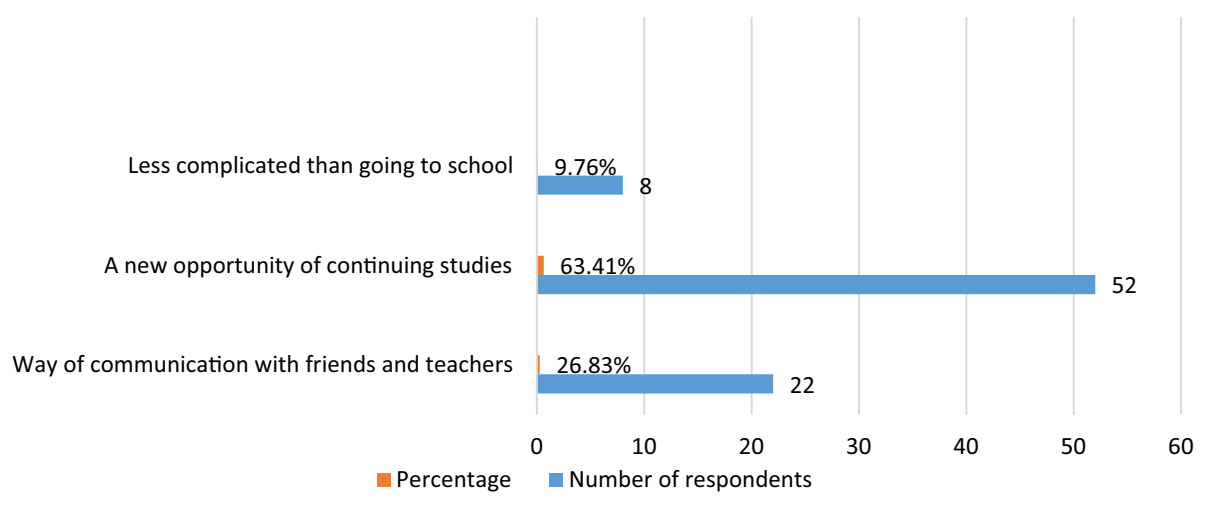

Figure 4 Reasons for liking online classes

A similar statement was made by a 10 -year-old respondent from a Bangla medium school, who stated, "I like online classes because at least I can see my friends and teachers. It also helps me to come out from my monotonous life".

On the other hand, some respondents stated that they do not like online classes (Figure 5). A 12-year-old student from an English-version school in Dhaka stated,

Sometimes I cannot understand many lessons and teachers take time to reply. I cannot ask my require questions properly. This online class is not comfortable at all. Sometimes, because of poor internet connection, I can't hear teacher's voice clearly. This makes me worry.

A 6-year-old respondent from an English-version medium school wanted to meet her friends and said,

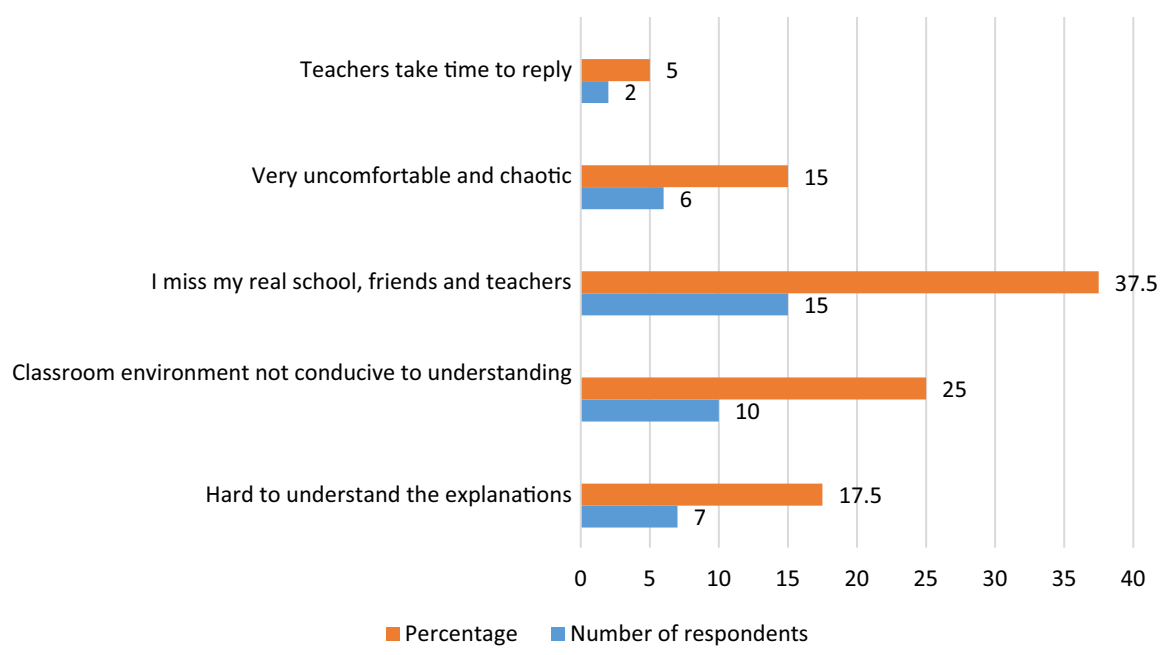

Figure 5 Reasons for not liking online classes 
I am missing my friends. I have two friends in my class. We used to play and take tiffin [box lunch] together. In our online classes, my mother helped me to connect with the class teacher. There I cannot talk with my friends. I know they are missing me too.

\section{Information about leisure time during the lockdown}

The "vacation" during Covid-19 provided children with unlimited leisure time. Instead of going to school, spending time with friends and teachers, and playing at the schoolground, they were confined in their homes. We investigated their activities during leisure time (Figure 6). Seventy-five percent of the respondents browsed the internet during their leisure time. In contrast, only $53 \%$ of the respondents read storybooks. Spending time with family members was a popular choice for their leisure time. Playing with siblings (55\%) and cultural activities (68\%) such as singing, dancing, and drawing were other preferred activities for leisure time (Figure 7).

Although $75.0 \%$ of the respondents reported they used the internet during their leisure time, $98.0 \%$ claimed they use the internet out of necessity. Most $(57.0 \%)$ used their mobile phone to access the internet either during their leisure time or a formal time (class). Only 9.9\% of the respondents used the internet only for online classes. Apart from online classes, the respondents used the internet to listen to music, chat with friends, and watch movies or serial dramas $(54.5 \%, 50.4 \%$, and $39.7 \%$, respectively). Virtually all parents $(99.2 \%)$ of the respondents knew their children were using the internet. Slightly more than half $(55.1 \%)$ of the respondents used the internet for 1 to 3 hours per day, and $42.9 \%$ of the respondents claimed their parents never scolded them for using the internet (Table 3).

A 16-year-old respondent from a Bangla medium school admitted she knew it was not good to use the internet too much, but she could not stop herself from using it. In her words:

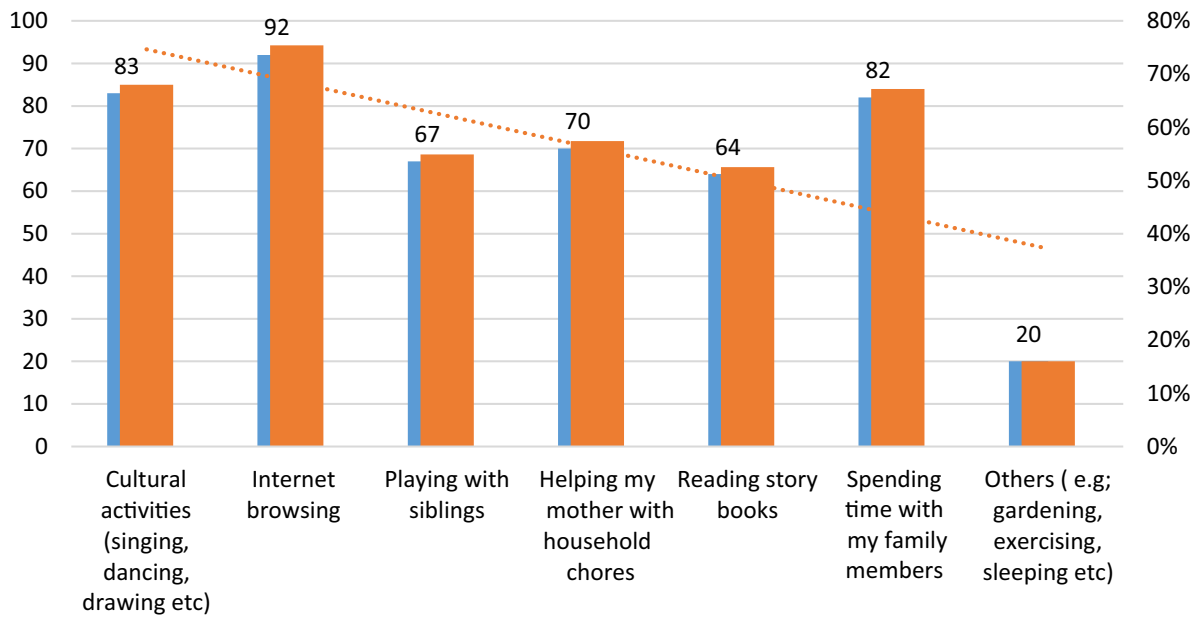

Number of respondents $\quad$ Percentage

Figure 6 Leisure time activities (multiple answers were counted) 


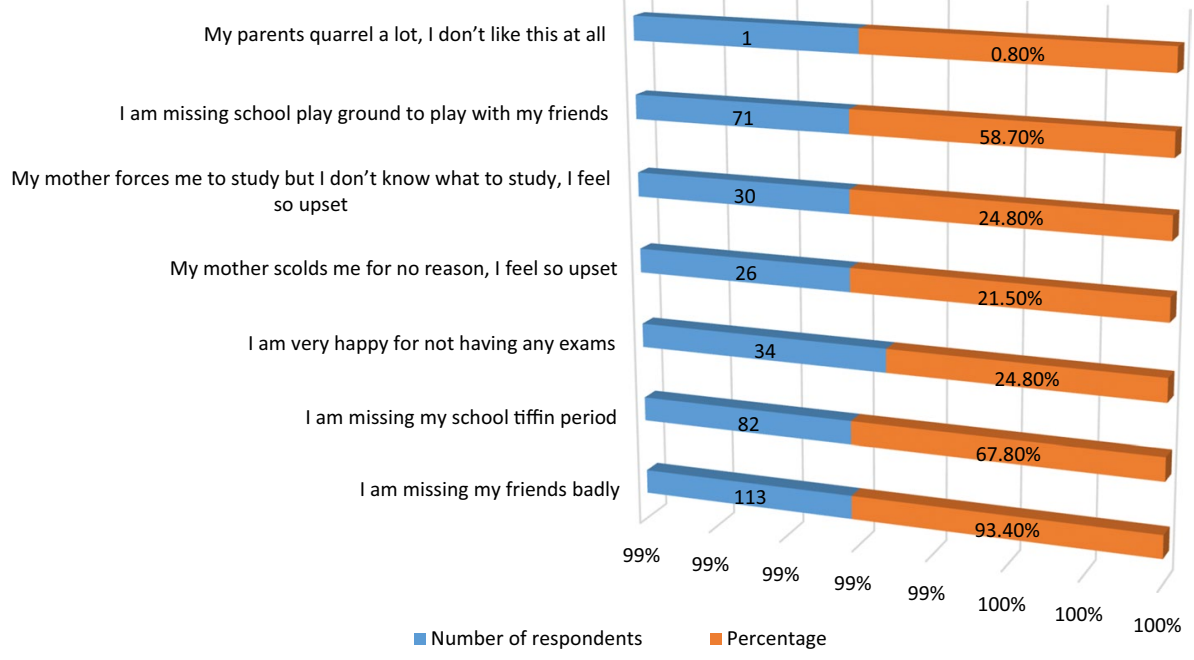

Figure 7 Effects of long vacation on children (more than one answer was counted)

I really want the human connection. I miss my friends very much. I am in grade 10 now. Next year I have the Secondary School Certificate examination but all of a sudden all my classes and tuitions are stopped. It is already four months since we do not have any target of any competition. We used to share all our happiness and sorrow with our friends. But now, what more we can do except sharing all out feelings with internet browsing! By chatting with them I reduce my stress. Beside this, I use it for watching movies. This is how I use internet for more than 5 hours per day. My mother knows it. But she also does not have any alternative.

The children understood the reason for the long vacation, but $78.7 \%$ wanted their school to be reopened very soon. Due to the vacation, they (93.4\%) missed their friends. Furthermore, most of them (67.8\%) missed their school's tiffin period. More than half of the respondents $(58.7 \%)$ missed their school playground, where they used to play with their friends. Almost one-quarter (24.8\%) of the respondents said their mother forced them to study, but they did not know what they should study during the vacation. Moreover, $21.5 \%$ of the respondents said they were upset because their mothers scolded them for no reason.

\section{Role of the school and changes in socialization}

During the Covid-19 pandemic, students at schools in the urban area of Dhaka were targeted to complete their academic syllabus through online classes. Some schools were partially successful in delivering lessons and completing their academic curriculum, although they lacked face-to-face interactions. Schools were unable to introduce students to their social world. Online classes could not teach them the norms and values of discipline, teamwork, compromising, and sacrificing for teammates and groups. Peer relationships could not be nurtured in the virtual classroom. Students could not become self-reliant and independent, because they did not get a chance to make decisions and lead a group in the school setting. If the school 
Table 3 Use of the internet during vacation

\begin{tabular}{|c|c|}
\hline Item & $n(\%)$ \\
\hline \multicolumn{2}{|c|}{ Do you use the internet during the vacation? } \\
\hline Yes & $120(98.4 \%)$ \\
\hline No & $2(1.6 \%)$ \\
\hline \multicolumn{2}{|c|}{ How many hours do you use the internet in a day? } \\
\hline Less than 1 hour & $27(22.9 \%)$ \\
\hline $1-3$ hours & $65(55.1 \%)$ \\
\hline $3-5$ hours & $12(10.2 \%)$ \\
\hline More than 5 hours & $14(11.9 \%)$ \\
\hline \multicolumn{2}{|c|}{ What device do you use to go on the internet? } \\
\hline Mobile & $69(57.0 \%)$ \\
\hline Laptop & $26(21.5 \%)$ \\
\hline Desktop & $9(7.4 \%)$ \\
\hline Others (e.g., TV, iPad) & $18(14.7 \%)$ \\
\hline \multicolumn{2}{|c|}{$\begin{array}{l}\text { What activities do you do with the internet? (more than } \\
\text { one answer was counted) }\end{array}$} \\
\hline Chatting with friends & $61(50.4 \%)$ \\
\hline Watching movie/serial drama & $48(39.7 \%)$ \\
\hline Using social media & $26(21.5)$ \\
\hline Watching cartoons & $39(32.2 \%)$ \\
\hline Listening to music & $66(54.5 \%)$ \\
\hline Doing online classes & $12(9.9 \%)$ \\
\hline Playing games & $8(6.6 \%)$ \\
\hline All the above & $11(9.1 \%)$ \\
\hline None of the above & $3(2.5 \%)$ \\
\hline Other activities & $3(2.5 \%)$ \\
\hline \multicolumn{2}{|c|}{ Do your parents know about your internet use? } \\
\hline Yes & $119(99.2 \%)$ \\
\hline No & $0(0 \%)$ \\
\hline Maybe & $1(0.8 \%)$ \\
\hline \multicolumn{2}{|c|}{ Do your parents scold you for using the internet? } \\
\hline Yes & $69(57.1 \%)$ \\
\hline No & $51(42.9 \%)$ \\
\hline \multicolumn{2}{|c|}{ Do you want your school to be reopened very soon? } \\
\hline Yes & $96(78.7 \%)$ \\
\hline No & $26(21.3 \%)$ \\
\hline
\end{tabular}

closure were to stretch longer and the authorities continued to provide online classes, the children's social learning would be interrupted, in addition to any negative health impact they might suffer. 


\section{Peer relationship effect}

In school, children share their experiences with their peers. In the urban areas of Bangladesh, the number of children a family can have is controlled by the family planning project introduced by the government. Moreover, in Dhaka, most families are nuclear in nature. For these reasons, the school plays a key role in building social relationships in the absence of siblings and extended family members. But during the pandemic, home confinement and school closures have affected the development of peer relationships. Peers can judge good behavior and positive thinking, but it is impossible for them to practice these skills in online classes. Students do not have psychological support from their peers in the absence of group work and the opportunity to develop emotional attachments.

\section{Distress and psychiatric conditions}

Children are used to staying in their schools every weekday for more than 5 hours, on average, which has been interrupted for the past 4 months and potentially for an indefinite time. Nowadays, in Dhaka, children do not have fields and parks in which to play with their friends. Most schools can fill this gap. During tiffin and sports time, children play together with their friends. These activities keep them physically fit and psychologically cheerful. However, due to their indefinite vacation, children missed having friends and peers with whom they could share their emotions and feelings. In addition, domestic violence involving children increased during the vacation, due to parents torturing them psychologically for studying continuously, not doing household chores, and more. All these issues can cause anxiety and stress. This situation may cause a long-term negative impact on children's psychological health.

\section{Excessive use of media}

Due to the absence of school settings, teachers, and peer groups, children have been idle at home with their infinite vacation during the pandemic. To keep themselves busy, young people are dependent on the media and internet. Online classes permit them to use various media to obtain news, which then becomes their habitual way to stay connected with the wider society and to learn about culture and society through movies, cartoons, video games, and other sources of information. The internet provides them with a way to stay connected with their friends and peers. These sources become alternative agents of socialization in the absence of formal schools. Moreover, students do not have enough work to pass the time. Therefore, their parents allow them to use the internet for an unlimited time. This situation may make them vulnerable to being virtually abused by known or unknown sources. 


\section{Online classes cannot be the alternative for traditional classes}

Online classes can be accepted during a pandemic, but they are not the solution for long-term planning. The findings revealed that most children in Bangladesh used a mobile phone screen for their class and looked at the small screen for long periods, which can be harmful for young members of society. Except for allowing students to continue and complete a syllabus, online classes did not have a positive impact on them. Instead, these classes were very uncomfortable, chaotic, and did not enable communication with friends and teachers. Therefore, they are considered a nonresponsive medium for learning. For young children, online classes require the help of their parents to operate the system. Thus, parents need to be educated and skilled to use online learning; otherwise, the system of online classes will collapse.

\section{Family remains the primary agent of socialization}

Throughout the world, family is the primary agent of socialization. During the pandemic, this agent remained the primary agent of socialization for children. The role of schools was changed and reshaped, but the role of the family remained unchanged. Family roles (e.g., parents, siblings, and other extended members) change as children spend more time with their parents, play games with their siblings, and share emotions with their family members. This is how they learn the norms, values, and cultural skills that equip them to become better future citizens.

\section{Online classes may generate inequality among the children}

Not all schools offer online classes. Therefore, children who get an online class opportunity may feel superior to those who are not given the opportunity. This situation is not good for future generations in Bangladesh. Similarly, children who do have online classes do not get the same newspapers and technological support as other children, which may create a feeling of deprivation. All these inequalities will have a negative effect on the socialization of the children.

\section{Other sources of learning and socialization}

During their vacation, children get unlimited time. They are not pressured with homework and examinations; they can read storybooks, listen to music, and enjoy movies. These activities become new sources of information about the social world, making children more knowledgeable and a part of society. 


\section{Conclusion}

Online classes cannot be an alternative to traditional schools. Online classes can only be used for a short time, due to their technological limitations and inability to provide complete learning for students. Moreover, a school provides multidimensional services to students, including building peer relations, making them more disciplined and independent, and creating a suitable environment for teamwork. Virtual classes only provide children with partial and substandard learning. They may complete a syllabus but cannot become skilled and fully functional members of society. They become more dependent on media than on their social relationships with peers, teachers, and others. This situation may influence them to become overly introverted and make it harder for them to fit into society. Moreover, not all children get an equal chance to participate in online classes, which can create educational inequalities.

\section{References}

Altena, E., Baglioni, C., Espie, C. A., Ellis, J., Gavriloff, D., Holzinger, B., et al. (2020). Dealing with sleep problems during home confinement due to the Covid-19 outbreak: Practical recommendations from a task force of the European CBT-I Academy. Journal of Sleep Research, 238, e13052.

Armitage, R., \& Nellums, L. B. (2020). Considering inequalities in the school closure response to Covid-19. The Lancet Global Health, 8(5), e644.

Bethune, Z. A., \& Korinek, A. (2020). Covid-19 infection externalities: Trading off lives vs. livelihoods. National Bureau of Economic Research. https://www.nber.org/system/files/working_papers/ w27009/w27009.pdf

Bhimraj, A., Morgan, R. L., Shumaker, A. H., Lavergne, V., Baden, L., Cheng, V. C. C., Edwards, K. M., Gandhi, R., Gallagher, J., Muller, W. J., O’Horo, J.C., Shoham, S., Murad, M. H., Mustafa, R. A., Sultan, S., \& Falck-Ytter, Y. (2020). Infectious Diseases Society of America guidelines on the treatment and management of patients with Covid-19. Clinical Infectious Diseases. https://www.porta ilvasculaire.fr/sites/default/files/docs/2020_idsa_covid-19_guidelines_0.pdf

Bhutani, S., \& Cooper, J. A. (2020). Covid-19 related home confinement in adults: Weight gain risks and opportunities. Obesity, 28(9), 1576-1577.

Child, T. L. (2020). Pandemic school closures: risks and opportunities. The Lancet Child and Adolescent Health, 4(5), 341.

Dev, S. M., \& Sengupta, R. (2020). Covid-19: Impact on the Indian economy. Indira Gandhi Institute of Development Research. http://www.igidr.ac.in/pdf/publication/WP-2020-013.pdf

Dong, E., Du, H., \& Gardner, L. (2020). An interactive web-based dashboard to track Covid-19 in real time. The Lancet Infectious Diseases, 20(5), 533-534.

Hanafiah, K. M., Ayub, A. J., \& Wai, G. H. (2020). Dancing with Covid-19: Public health precautions beyond the movement control order. http://www.krinstitute.org/assets/contentMS/img/template/editor/200427_Dancing\%20with\%20COVID19_FINAL\%20(003).pdf

Lee, P. I., Hu, Y. L., Chen, P. Y., Huang, Y. C., \& Hsueh, P. R. (2020). Are children less susceptible to COVID-19? Journal of Microbiology, Immunology, and Infection., 53(3), 371-372. https://doi.org/ 10.1016/j.jmii.2020.02.011.

Mehta, P., McAuley, D. F., Brown, M., Sanchez, E., Tattersall, R. S., Manson, J. J., \& HLH Across Specialty Collaboration (2020). COVID-19: Consider cytokine storm syndromes and immunosuppression. Lancet, 395(10229), 1033.

Mustari, S., \& Rahman, M. Z. (2020). The effect of the corona disaster on women: Lockdown and corona virus from the lens of social science. SocArXiv. https://doi.org/10.31235/osf.io/4e63c.

Parke, R. D., \& Buriel, R. (2007). Socialization in the family: Ethnic and ecological perspectives. Handbook of Child Psychology, 3, 429-504. https://doi.org/10.1002/9780470147658.chpsy0308.

Putwain, D. (2007). Researching academic stress and anxiety in students: Some methodological considerations. British Educational Research Journal, 33(2), 207-219. 
Qiu, J., Shen, B., Zhao, M., Wang, Z., Xie, B., \& Xu, Y. (2020). A nationwide survey of psychological distress among Chinese people in the COVID-19 epidemic: Implications and policy recommendations. General Psychiatry, 33(2). 1-4. https://gpsych.bmj.com/content/gpsych/33/2/e100213.full.pdf

Remuzzi, A., \& Remuzzi, G. (2020). COVID-19 and Italy: What next? The Lancet, 395(10231), 1225-1228.

Sinha, I. P., Harwood, R., Semple, M. G., Hawcutt, D. B., Thursfield, R., Narayan, O., et al. (2020). COVID19 infection in children. The Lancet Respiratory Medicine, 8(5), 446-447.

Xie, X., Xue, Q., Zhou, Y., Zhu, K., Liu, Q., Zhang, J., \& Song, R. (2020). Mental health status among children in home confinement during the coronavirus disease 2019 outbreak in Hubei Province, Chine. JAMA Pediatrics, 174(9), 898-900. https://doi.org/10.1001/jamapediatrics.2020.1619.

Publisher's Note Springer Nature remains neutral with regard to jurisdictional claims in published maps and institutional affiliations.

Sohela Mustari is an assistant professor at the Department of Sociology, Begum Rokeya University, Rangpur. She obtained her PhD from International Islamic University Malaysia (IIUM), where she focused on the vulnerabilities and resiliency of the Coastal People of Bangladesh. Currently, she is working on a number of government and non-government projects related to climate change, migration, Covid-19, and other social issues. Mustari obtained her bachelor's and master's degrees in sociology from the University of Dhaka. She has experience working with women in Bangladesh, strengthening their leadership and entrepreneurship abilities, through research funded by UN Women and BRAC University. She has published research articles in national and international journals and has written newspaper editorials on various social issues.

Mehe Zebunnesa Rahman is the director of the BBA Program and assistant professor at the School of Business and Economics (SBE) at North South University (NSU). She completed her PhD from National University of Malaysia, with the support of the Commonwealth Scholarship Fellowship Plan. She earned her bachelor's and master's degrees in agricultural economics from Bangladesh Agricultural University, with highest distinctions, and received a gold medal. She is the facilitator for Strengthening Market Access for Women-Owned Businesses in Bangladesh, sponsored by WE Connect International. She is also involved in developing entrepreneurship in Bangladesh and has been collaborating with NSU and City Bank, Bangladesh, for women and rural entrepreneurship development programs.

Susmita Kar has completed her MA in public health (MPH) from Daffodil International University, Dhaka, Bangladesh. Currently, she is involved in various health and social research projects as a freelance research assistant. Her quantitative research is focused on VIA, PEP, and KAP testing of cervical cancer in urban women, and she has published results in national and international journals. 